\title{
Improvement of the Heat Balance Equation Accuracy, in the Case of Saturation Diving
}

\author{
Anca Constantin*, Tamara Stanciu
}

\begin{abstract}
The body temperature of a diver is one of the most important aspects of the concept of underwater safety and comfort. The heat balance equation previously established, was improved in this paper by introducing a linear dependence of the absolute humidity on the body temperature, as the absolute humidity influences the latent heat flux needed for the humidification of the breathing gas. The solution of the new proposed heat balance equation is a step forward in assessing the body temperature in both cases of unitary and saturation diving. The paper presents the equation and its solutions in the case of breathing either air or Heliox and compares the theoretical results with the values measured in the frame of simulated saturation diving with Heliox $5 / 95$, in the hyperbaic laboratory. The proposed equation predicts the body temperature of the diver, at the end of a 30 minutes immersion with a good accuracy. The relative error is up to $1 \%$.
\end{abstract}

Keywords: body temperature; heat balance; saturation diving

\section{INTRODUCTION}

The diving technology has impressively evolved in the last decade allowing man to safely work in underwater sites for longer periods of time and with extended respiratory and thermal comfort. Beside the researches regarding breathing apparatuses and respiratory mixtures, the interest on thermal mechanisms in underwater environment has been the object of study for researchers from our country and from abroad. Depending on the diving plan, the temperature reached by the diver's body after the immersion time has to be assessed prior to the diving, so that the most appropriate thermal protection strategy to be taken to avoid hypothermia temperature ( 28 $\left.{ }^{\circ} \mathrm{C}\right)$ [1]. Thermal protection strategies are passive and active. Passive strategies consist in covering the diver with an insulating layer (diving suit). Active strategies use an external source of energy to compensate for the body's heat loss, the most common being a hot water suit. Other systems use electrical resistors attached to the undergarment [2].

Tarlochan [3] studied the thermal comfort of a swimmer, which means the heat lost by a human body in seawater, but at atmospheric pressure and without any protection suit. The theoretical and experimental studies of Majchrzycka [4], and King [5] referred to a human body in pressurized facilities, but in dry environment. The temperature distribution in the atmosphere of the dry hyperbaric chamber, provided by the specific thermal conditioning installations [6], influences the heat losses of the divers at saturation.

The studies on heat loss mechanisms developed in the Diving Centre in Constanta refer to divers immersed in water, in controlled conditions which simulate the water pressure at different depths [7].

The experimental assessment of the heat lost by a diver showed thermal losses of a diver are approximately two times higher when using Heliox instead of air as breathing mixture, under similar conditions of water temperature and depth, in the first $15 \mathrm{~min}$ of simulated diving [8]. The density of the heat flux lost by a diver which breathes air is around 400 $\mathrm{W} / \mathrm{m}^{2}[9]$.

The working depth of more than $50 \mathrm{~m}$ requires the use of another diluent gas (usually helium) for oxygen, instead of nitrogen from the atmospheric air. The use of the binary respiratory mixture Heliox, that means oxygen diluted by helium, and the increase of the range of immersion depths, determine different thermal phenomena, due to the physical properties of helium, very different from those of nitrogen. Hyperbaric conditions and the range of saturation dives also influence the heat exchange between the diver's body and the environment. The phenomena are complex and have been studied both theoretically and practically, through a series of tests performed at the Hyperbaric Laboratory of the Diving Center.

In [10] it is proposed an equation that describes, with good accuracy, the variation of the diver's temperature, considering all categories of heat loss in the case of air as breathing mixture. The equation was written assuming the humidification of the inhaled air is made at a vapor pressure corresponding to the body temperature of $37^{\circ} \mathrm{C}$. It showed a good accuracy when the results were compared to the experimental data, but a correction coefficient was needed. Stanciu $[10,11]$ proposed the correction coefficient $c_{\text {air }}=-$ $0.5^{\circ} \mathrm{C}$.

In this paper, we continue the work regarding saturation diving and the diver's temperature during immersion in saturation, aiming to adapt the equation to the case the diver breathes Heliox 5/95, the binary mixture with 5\% Hellium. The theoretical model is validated by the experimental results obtained in the Hyperbaric Laboratory.

\section{THE EQUATION THAT GOVERNS THE DIVER'S TEMPERATURE VARIATION DURING IMMERSION}

The heat balance equation considers the heat flux produced by diver's metabolism, the heat flux lost by the diver at the skin level, and the heat flux lost due to the heating and humidification of the respiratory gas during the inhalation process [9].

$$
\begin{aligned}
& m c_{\mathrm{b}} \frac{\mathrm{d} T}{\mathrm{~d} t}= \\
& =\dot{Q}_{\mathrm{m}}-\frac{T-T_{\mathrm{w}}}{R_{(p)}} A-l_{(p)} \rho_{(p)} x_{(p)} \dot{V}_{(p)}-\rho_{(p)} c \dot{V}_{(p)}\left(T-T_{\mathrm{w}}\right),
\end{aligned}
$$


were $m$ - mass of the diver's body $(\mathrm{kg}) ; c_{\mathrm{b}}$ - specific heat of the human body $\left(3400 \mathrm{~J} /\left(\mathrm{kg} \cdot{ }^{\circ} \mathrm{C}\right)\right) ; T$ - body temperature of the diver $\left({ }^{\circ} \mathrm{C}\right) ; t$ - underwater exposure time $(\mathrm{s}) ; \dot{Q}_{\mathrm{m}}-$ metabolic heat flux $(\mathrm{W}) ; T_{\mathrm{w}}$ - water temperature $\left({ }^{\circ} \mathrm{C}\right) ; R_{(p)}$ human skin thermal resistance $\left(\mathrm{m}^{2} \cdot{ }^{\circ} \mathrm{C} / \mathrm{W}\right) ; l_{(p)}$ - water specific latent heat $(\mathrm{J} / \mathrm{kg}) ; \rho_{(p)}$ - air density $\left(\mathrm{kg} / \mathrm{m}^{3}\right) ; x_{(p)}$ absolute humidity of the breathing $\operatorname{gas}(\mathrm{kg} / \mathrm{kg}) ; \dot{V}_{(p)}-$ breathing flow rate in normal conditions of pressure $\left(\mathrm{m}^{3} / \mathrm{s}\right) ; c$ - air specific heat at constant pressure $\left(1010 \cdot \mathrm{J} / \mathrm{kg} \cdot{ }^{\circ} \mathrm{C}\right)$. One may notice that the pressure is a parameter in this equation.

This mathematical model for temperature variation was built assuming the breathing gas is saturated with water vapors during an inhalation, considering the vapors saturation pressure of $p_{\mathrm{v}}=0.0628$ bar at the average human body core temperature of $37^{\circ} \mathrm{C}$. That means the absolute humidity $x$ was considered constant with the temperature. But it depends on saturation pressure of vapors that means it depends on body temperature [12] and the body temperature is the variable of this equation.

$x=\frac{m_{\mathrm{v}}}{m_{\mathrm{a}}}=\frac{p_{\mathrm{v}} R_{\mathrm{a}}}{p_{\mathrm{a}} R_{\mathrm{v}}}=\frac{R_{\mathrm{a}}}{R_{\mathrm{v}}} \cdot \frac{p_{\mathrm{v}}}{p_{\mathrm{am}}-p_{\mathrm{v}}}$,

where $R_{\mathrm{a}}=287 \mathrm{~J} /\left(\mathrm{kg} \cdot{ }^{\circ} \mathrm{C}\right)$ - air constant; $R_{\mathrm{v}}=462 \mathrm{~J} /\left(\mathrm{kg} \cdot{ }^{\circ} \mathrm{C}\right)$ - Heliox constant.

The solution of the Eq. (1) led to unsatisfying results when applied to Heliox as breathing mixture. Therefore, we dropped the assumption the breathing gas is saturated up to the core temperature of $37{ }^{\circ} \mathrm{C}$, and replaced the constant absolute humidity $x_{(p)}$ with a function of the body temperature, $T$.

We considered a linear dependence of the humidity over temperature and obtained the following functions: (3) for air and (4) for Heliox 5/95, at a water depth of $60 \mathrm{~m}$.

$$
\begin{aligned}
& x_{(T)}=0.0003 \cdot T-0.005 \\
& x_{(T)}=0.0004 \cdot T-0.0062
\end{aligned}
$$

Therefore, the Eq. (1) was reshaped and became, in the case of air breathing:

$$
\begin{aligned}
& m c_{\mathrm{b}} \frac{\mathrm{d} T}{\mathrm{~d} t}=\dot{Q}_{\mathrm{m}}-\frac{T-T_{\mathrm{w}}}{R_{(p)}} A- \\
& -l_{(p)} \rho_{(p)} \dot{V}_{(p)}(0.0003 \cdot T-0.005)-\rho_{(p)} c \dot{V}_{(p)}\left(T-T_{\mathrm{w}}\right),
\end{aligned}
$$

and, in the case of Heliox breathing:

$$
\begin{aligned}
& m c_{\mathrm{b}} \frac{\mathrm{d} T}{\mathrm{~d} t}=\dot{Q}_{\mathrm{m}}-\frac{T-T_{\mathrm{w}}}{R_{(p)}} A- \\
& -l_{(p)} \rho_{(p)} \dot{V}_{(p)}(0.0004 \cdot T-0.0062)-\rho_{(p)} c \dot{V}_{(p)}\left(T-T_{\mathrm{w}}\right)
\end{aligned}
$$

The solution of the Eq. (5) or (6) is:

$$
T=\left(T_{\mathrm{o}}-T_{\mathrm{w}}-\frac{a}{b}\right) \cdot \mathrm{e}^{-b t}+\frac{a}{b}+T_{\mathrm{w}}
$$

Where the coefficients $a$ and $b$ are written for the two breathing gases as follows:

Air

$$
\begin{aligned}
& a=\frac{\dot{Q}_{\mathrm{m}}-0.0003 \cdot T_{w} l_{(p)} \rho_{(p)} \dot{V}_{(p)}+0.005 \cdot l_{(p)} \rho_{(p)} \dot{V}_{(p)}}{m c_{\mathrm{b}}} \\
& b=\frac{\frac{A}{R_{(p)}}+\rho_{(p)} c \dot{V}_{(p)}-0.0003 \cdot l_{(p)} \rho_{(p)} \dot{V}_{(p)}}{m c_{\mathrm{b}}}
\end{aligned}
$$

Heliox

$$
\begin{aligned}
& a=\frac{\dot{Q}_{\mathrm{m}}-0.0004 \cdot T_{w} l_{(p)} \rho_{(p)} \dot{V}_{(p)}+0.0062 \cdot l_{(p)} \rho_{(p)} \dot{V}_{(p)}}{m c_{\mathrm{b}}} \\
& b=\frac{\frac{A}{R_{(p)}}+\rho_{(p)} c \dot{V}_{(p)}-0.0004 \cdot l_{(p)} \rho_{(p)} \dot{V}_{(p)}}{m c_{\mathrm{b}}}
\end{aligned}
$$

\section{THEORETICAL RESULTS}

The solution (7) was graphically represented in Fig. 1, considering a diver with the following features: body mass $m$ $=84 \mathrm{~kg}$, height $h=1.78 \mathrm{~m}$, age $a=42$ year; body surface $S$ $=2.05 \mathrm{~m}^{2}$ and a production of metabolic heat $\dot{Q}=88 \mathrm{~W}$. The diver is one of the four divers that participated in simulated saturation diving series in the hyperbaric laboratory of the Diving Centre [7].

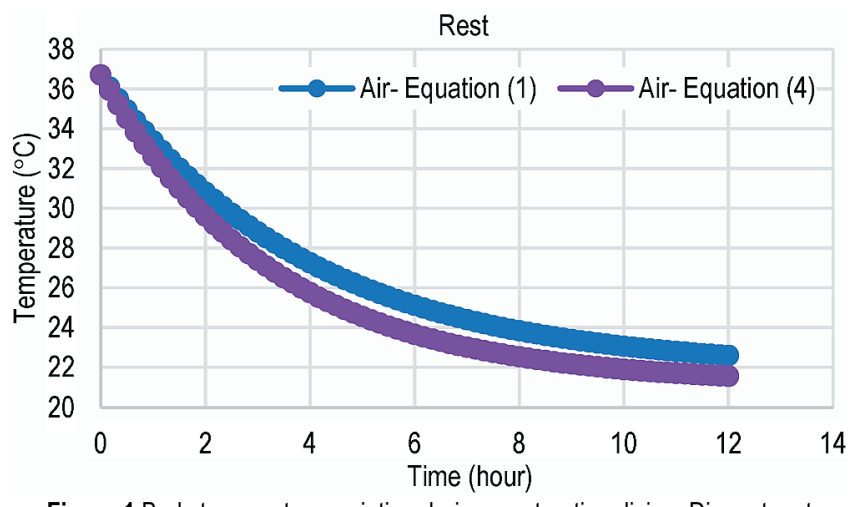

Figure 1 Body temperature variation during a saturation diving. Diver at rest

In Fig. 1 it may be noticed that the Eq. (5) gives smaller temperature values than Eq. (1), and the difference is quite equal to the correction coefficient $c_{\text {aer }}=-0.5^{\circ} \mathrm{C}$, proposed by Stanciu $[10,11]$.

The Eq. (1) introduces errors as the temperature during air breathing diving decreases faster than during the Heliox breathing diving. The solution of the reshaped Eqs. (5) and (6) give an appropriate variation of temperature, in 
accordance with the thermal flux lost by a diver in the abovementioned conditions of gas breathing. The curves in Fig. 2 show a more realistic decrease of the human body temperature: the temperature decreases faster when the diver breathes Heliox. The body temperature settles at $T=21{ }^{\circ} \mathrm{C}$, as the water temperature is $T_{\mathrm{w}}=19.5^{\circ} \mathrm{C}$. The graphs in the Fig. 3 were theoretically plotted. The curves were plotted for a period of 12 hours, as the allure is more visible for such a long time. Actually, the time spent by a diver in immersion during saturated diving is much shorter. The experiments in the simulator lasted for only $30 \mathrm{~min}$, which is a more realistic period.

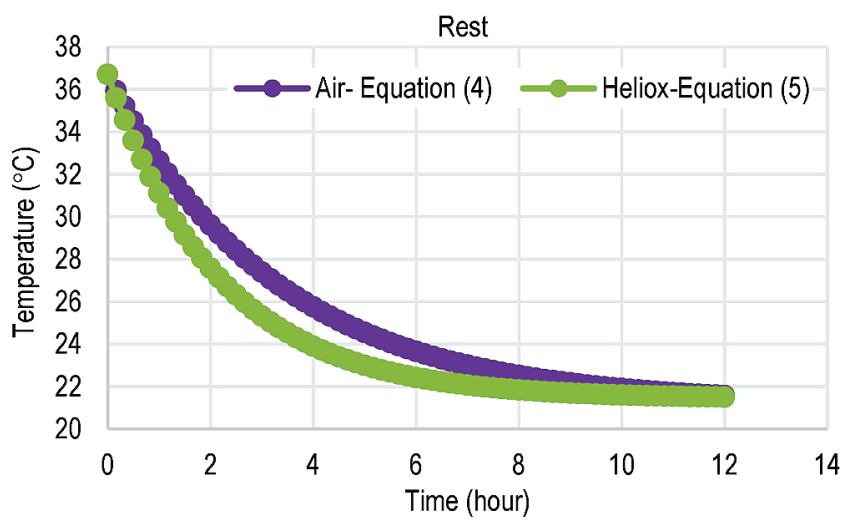

Figure 2 Body temperature variation, during similar saturation diving with air and with Heliox. Diver at rest

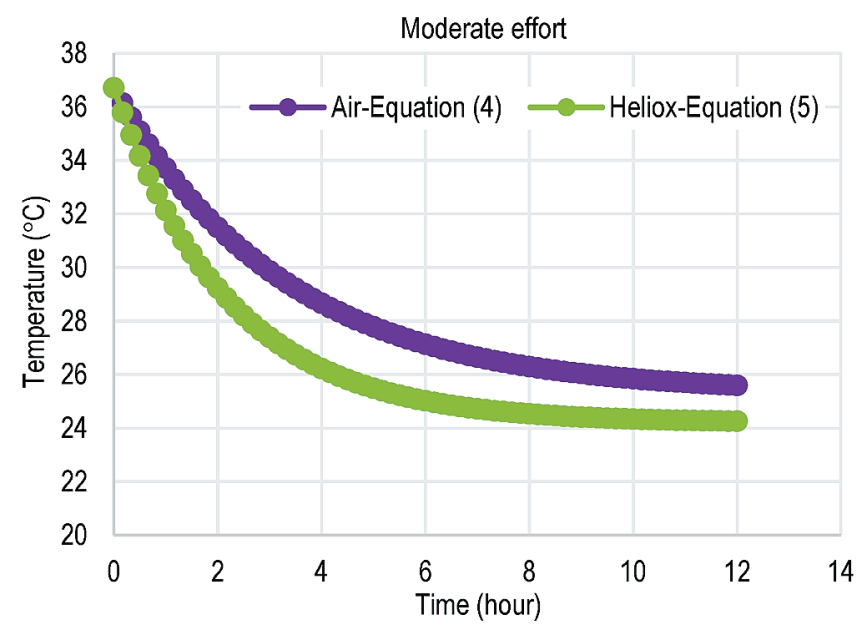

Figure 3. Body temperature variation during a saturation diving. Diver performs moderate effort (100 W)

Similar graphs were represented in Fig. 3, but it was taken into account an increased metabolic heat flux, produced by a moderate effort, of $100 \mathrm{~W}$, performed by the diver during immersion. Temperature decreases more slowly, and it settles around $T=26^{\circ} \mathrm{C}$ for air and $T=24.3$ ${ }^{\circ} \mathrm{C}$ for Heliox.

\section{EXPERIMENTAL MEASUREMENTS}

The simulated diving series were carried out in the hyperbaric laboratory of the Diving Centre, Fig. 4.

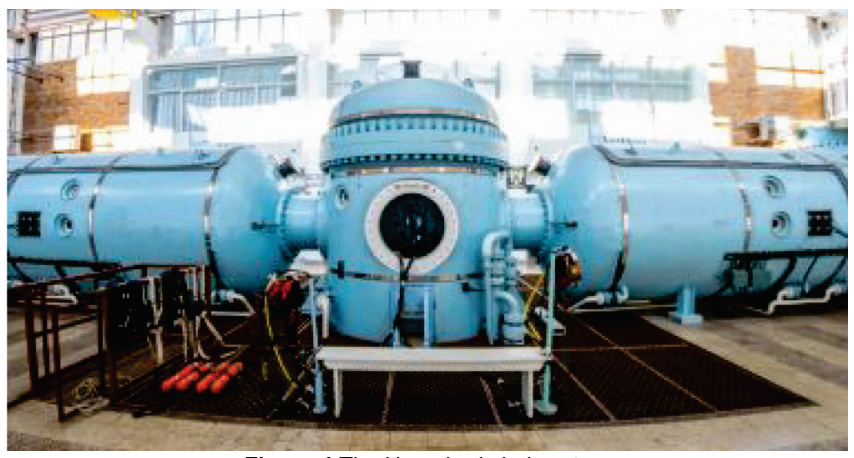

Figure 4 The Hyperbaric Laboratory

(Diving Center photo archive)

The experiments comprised simulated saturation diving both with air and with Heliox mixture, at surface level and at different depths, simulated in the wet chamber of the laboratory. The entrance of a diver in the wet chamber is captured in Fig. 5.

We have to mention that all the measurements made at surface level may be referred to as made in saturation, as the human body is saturated with Nitrogen in normal conditions of pressure when breathing air.

Three divers performed the air diving series and four divers, the Heliox 5/95 diving series.

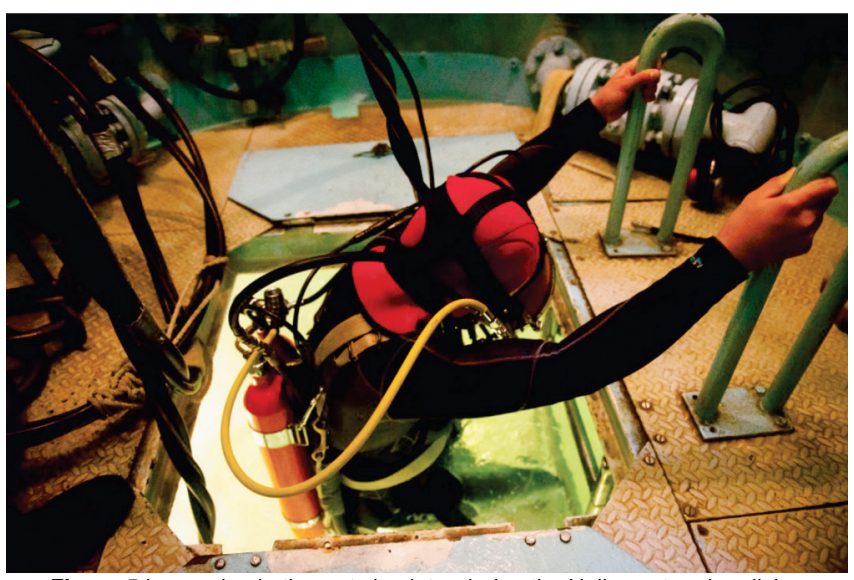

Figure $5 \mathrm{Immersion}$ in the wet simulator during the Heliox saturation diving (Diving Center photo archive)

The same physical amounts were measured at surface $(0$ $\mathrm{m}$ level) and at $61 \mathrm{~m}$ depth: $t_{\mathrm{i}}$ - the temperature of the inhaled breathing gas, $t_{\mathrm{e}}$ - the temperature of the exhaled breathing gas, $t_{\mathrm{c}}$ - the core temperature of the diver $\left({ }^{\circ} \mathrm{C}\right)$.

To measure the temperature, we used a professional thermometer immersed in the simulator and another thermometer, a digital one, for the diver's internal temperature. Their characteristics are given below.

The sensor immersed in the PROBE RTD GEN PURP 10 ANSI simulator, connected to the digital thermometer, has the following features:

- Temperature range: $-40 \div 150{ }^{\circ} \mathrm{C}$

- Response time: 4 sec

- ANSI connector

- Immersed stainless-steel sensor. 
The thermometer - mobile digital hygrometer features:

- Temperature range: $-50 \div 200{ }^{\circ} \mathrm{C}$

- Response time: $1 \mathrm{sec}$

- $\quad 1.5 \mathrm{~V}$ AAA batteries

- Immersed external sensor.

The surface technical team continuously monitored the divers inside hyperbaric chambers, during the two series of diving, as it may be seen in Fig. 6 .

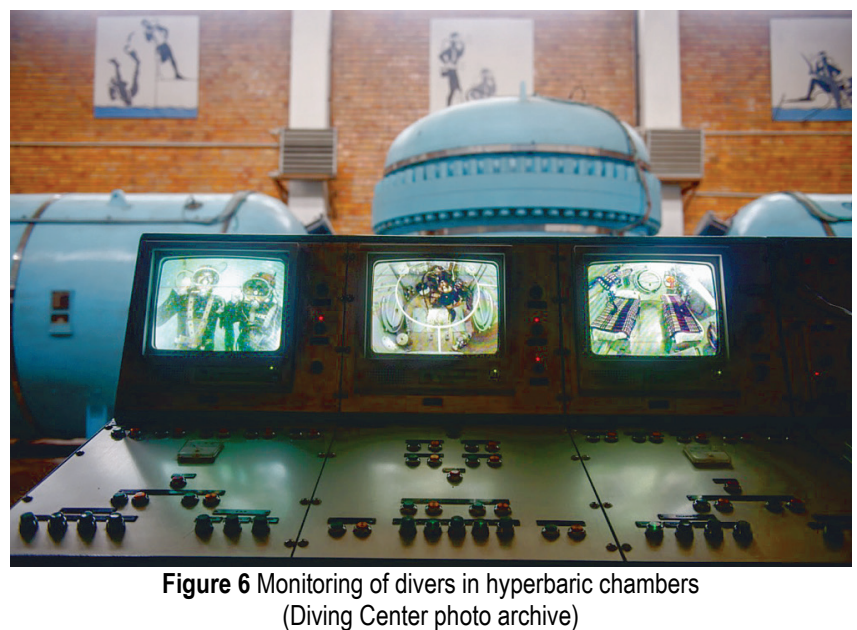

\section{DISCUSSION OF THEORETICAL AND EXPERIMENTAL DATA}

Experimental saturation diving is developed in the hyperbaric laboratory with a limited number of participants. Such experiments are hard to reproduce after a period, as the divers change, so it is difficult to compare the results. Therefore, we looked for divers with similar characteristics.

Only one of the divers that participated in the air diving series matched the main features of one of the divers diving in the Heliox series. They both had the same basic metabolic heat flux, of $88 \mathrm{~W}$, the same height, of $1.78 \mathrm{~m}$ and the same body area, of $2.05 \mathrm{~m}^{2}$. They were used to compare body temperature variation during air and Heliox diving, under name diver 2, in Tab. 1.

Table 1 Experimental data recorded during saturation diving with Heliox, at $61 \mathrm{~m}$ in depth. Divers performed moderate underwater effort (100 W)

\begin{tabular}{|c|c|c|c|c|c|}
\hline \multicolumn{2}{|c|}{ Diver } & 1 & 2 & 3 & 4 \\
\hline \multirow{3}{*}{ Surface } & $t_{\mathrm{i}}\left({ }^{\circ} \mathrm{C}\right)$ & 24 & 24 & 24 & 24 \\
\cline { 2 - 6 } & $t_{\mathrm{e}}\left({ }^{\circ} \mathrm{C}\right)$ & 33.5 & 32.8 & 31 & 31.9 \\
\cline { 2 - 6 } & $t_{\mathrm{c}}\left({ }^{\circ} \mathrm{C}\right)$ & 36.5 & 36.7 & 37 & 36.5 \\
\hline \multirow{3}{*}{ Depth: $61 \mathrm{~m}$} & $t_{\mathrm{i}}\left({ }^{\circ} \mathrm{C}\right)$ & 24 & 25 & 25 & 24 \\
\cline { 2 - 6 } & $t_{\mathrm{e}}\left({ }^{\circ} \mathrm{C}\right)$ & 34.5 & 34.1 & 34.1 & 34.2 \\
\cline { 2 - 6 } & $t_{\mathrm{c}}\left({ }^{\circ} \mathrm{C}\right)$ & 35.1 & 34.4 & 34.2 & 34.7 \\
\hline \multicolumn{2}{|c|}{ Exposure duration $(\mathrm{min})$} & 20 & 30 & 30 & 30 \\
\hline
\end{tabular}

The data collected in Tab. 1 refer to the Heliox saturation diving, in water with the temperature $T_{\mathrm{w}}=19.5^{\circ} \mathrm{C}$.

Regarding the body temperature variation during immersion, and the body temperature of a diver at the end of a certain exposure, it can be noticed a very good match between theoretical calculation and experimentally measured values, as shown in Tab. 2. The Eq. (6) proved a good prediction of the body temperature.

Table 2 Theoretical and experimental data at the end of a saturation diving with Heliox (61 m). Divers performed moderate underwater effort (100 W)

\begin{tabular}{|c|c|c|c|c|c|}
\hline \multicolumn{2}{|c|}{ Diver } & 1 & 2 & 3 & 4 \\
\hline \multicolumn{2}{|c|}{ Initial body temperature $\left({ }^{\circ} \mathrm{C}\right)$} & 36.5 & 36.7 & 37 & 36.5 \\
\hline \multicolumn{2}{|c|}{ Exposure duration $(\mathrm{min})$} & 20 & 30 & 30 & 30 \\
\hline $\begin{array}{c}\text { Body temperature } \\
\text { at the end of the } \\
\text { exposure }\left({ }^{\circ} \mathrm{C}\right)\end{array}$ & Theoretical & 35.2 & 34.3 & 34.5 & 34.4 \\
\cline { 2 - 7 } & Experimental & 35.1 & 34.4 & 34.2 & 34.7 \\
\hline
\end{tabular}

The relative error of the body temperature at the end of the immersion ranges between 0.3 and $1 \%$.

\section{CONCLUSIONS}

The interest in the diver's body temperature variation as a function of immersion duration, water temperature and the breathing mixture is justified by the importance of an appropriate preparation of the diver for diving, prior to immersion.

The multitude of physiological factors that influence the body temperature and the small number of subjects and experiments make the validation of the theoretical concepts very difficult.

Leaving the assumption that the absolute humidity depends only on pressure and not on body temperature, led to the improvement of the heat balance equation. The solution of the reshaped equation in which the absolute humidity has a linear variation with the body temperature proved to give a good prediction of the diver's body temperature. The experimental data measured during a saturation diving with Heliox 5/95, after 30 minutes of exposure showed a very good match with the theoretical values obtained for the body temperature, the relative error being comprised between 0.3 and $1 \%$. The new proposed equation may be used to assess the body temperature either with air or Heliox breathing mixture.

\section{Acknowledgments}

The authors want to recognize the merits of the divers of the Diving Center in Constanta, who participated in the tests and provided the logistics of the Hyperbaric Laboratory.

\section{REFERENCES}

[1] Dinu, D. \& Vlad, C. (1986). Scafandri şi vehicule subacvatice, Editura Ştiinţifică şi Enciclopedică, Bucureşti, pag. 88, 161163.

[2] U. S. Navy. (2018). Diving Manual, Rev. 7, Vol. 1, Direction of Commander Naval Sea Systems Command, USA.

[3] Tarlochan, F. \& Ramesh, S. (2005). Heat transfer model for predicting survival time in cold water immersion. Biomedical Engineering: Applications, Basis and Communications APPLICATIONS AND BASIS, 17(04), 159-166. https://doi.org/10.4015/S1016237205000251

[4] Majchrzycka, A. (2011). Model of Thermal Comfort in the Hyperbaric Facility. Polish Maritime Research, 1(68), vol 18, pp. 37-44, 1233-2585. 
https://doi.org/10.2478/v10012-011-0006-y

[5] King, F. G., Manson, H. J., Snellen, J. W. et al. (1984). Demonstration of a problem in estimating sensible heat loss from the respiratory tract by thermometry. Can Anaesth Soc J, 31, 460-465. https://doi.org/10.1007/BF03015426

[6] Volintiru, O. N., Scurtu, I. C., \& Ștefănescu, T. M. (2018), Modeling and optimization HVAC system for special ships, IOP Conf. Series: Journal of Physics Conf. Series 1122, IOP Publishing. https://doi.org/10.1088/1742-6596/1122/1/012004

[7] Stanciu, T. \& Diaconu, M. (2013). Experimental researches of thermal phenomenon during the saturation diving. Annals of the Oradea University, Management and Technological Engineering, Oradea, XXII(XII)(1), pp. 371. https://doi.org/10.15660/AUOFMTE.2013-1.2850

[8] Constantin, A. \& Stanciu, T. (2015). Thermic transfers during saturation dive. The $15^{\text {th }}$ International Multidisciplinary Scientific GeoConference SGEM, Marine and Ocean Ecosystems, Albena, Bulgaria, vol. 2, pp. 723-730, ISSN 13142704.

[9] Constantin, A. \& Stanciu, T. (2013). Transient heat transfer in subsea hyperbaric environment. The $13^{\text {th }}$ International Multidisciplinary Scientific GeoConference SGEM, Marine and Ocean Ecosystems, Albena, Bulgaria, pp. 871. https://doi.org/10.5593/SGEM2013/BC3/S15.008

[10] Stanciu, T. (2017). Validation of thermal balance equation of diver in hyperbaric environment at saturation with heliox. Journal of Marine Technology, I, pp. 45.

[11] Stanciu, T. (2018). Research on gas transfer in diving technologies, PhD Thesis, pp. 131, Library of Constanta Maritime University.

[12] Leonăchescu, N. (1981). Termotehnica, Editura Didactică şi Pedagogică, Bucureşti.

\section{Authors' contacts:}

\section{Anca Constantin, $\mathrm{PhD}$}

(Corresponding author)

Faculty of Civil Engineering, Ovidius University,

22b Unirii Str.,

900524 Constanta, Romania

Tel: +40742030709

E-mail: aconstantina@univ-ovidius.ro

Tamara Stanciu, $\mathrm{PhD}$

Diving Centre,

19, 1 May" Bvd.,

900524 Constanta, Romania

Tel: +40723297983

E-mail: tamara.stanciu@navy.ro 